\title{
Morphology, Thermal and Impedance Characteristics of Iodine Doped Metal Iodide-Epoxidized Natural Rubber (MI-ENR) Polymer Electrolytes
}

\author{
W.L.Tan ", M. Abu Bakar \\ School of Chemical Sciences, Universiti Sains Malaysia, 11800 Penang, Malaysia. \\ *E-mail: weileng728@gmail.com; weileng_tan@usm.my
}

doi: $10.20964 / 2016.10 .33$

Received: 7 June 2016 / Accepted: 29 July 2016 / Published: 6 September 2016

\begin{abstract}
A series of metal iodide-epoxidized natural rubber (MI-ENR) (where $\mathrm{M}=\mathrm{Li}, \mathrm{Na}, \mathrm{K}$ or $\mathrm{Ag}$ ) and their iodine $\left(\mathrm{I}_{2}\right)$ doped derivative $\left(\mathrm{I}_{2} / \mathrm{MI}-\mathrm{ENR}\right)$ polymer electrolytes (PEs) were successfully prepared via solvent casting method. The PEs were characterized using UV-vis, FTIR and SEM/X-mapping techniques. Their thermal properties were studied using DSC and TG analysis while the ionic conductivity characteristic was evaluated using the impedance spectroscopy. The glass transition temperature $\left(\mathrm{T}_{\mathrm{g}}\right)$ and impedance characteristics of the MI-ENR PEs is dependent on the solubility of MI salt in the ENR, the interaction of MI with ENR and the outcome morphology of the PE. The alkali metal iodides, $\mathrm{MI}(\mathrm{M}=\mathrm{Li}, \mathrm{Na}$ or $\mathrm{K})$ do not affect the thermal stability of ENR in the respective PEs. However, the AgI destabilized the ENR in the AgI-ENR PE. Doping the MI-ENR PEs with $\mathrm{I}_{2}$, caused increment in $\mathrm{T}_{\mathrm{g}}$, enhancement in thermal stability and changed the conduction mechanism.
\end{abstract}

Keywords: ENR, iodine, polymer electrolyte, metal iodide, thermal, impedance

\section{$\underline{\text { FULL TEXT }}$}

(C) 2016 The Authors. Published by ESG (www.electrochemsci.org). This article is an open access article distributed under the terms and conditions of the Creative Commons Attribution license (http://creativecommons.org/licenses/by/4.0/). 